\title{
Americium Transmutation in the SVBR-100 Reactor
}

\author{
A. V. Gulevich1, V. A. Eliseev¹, 0. G. Komlev², I. V. Tormyshev'1, G. I. Toshinsky 1,2* \\ ${ }^{1}$ JSC “SSC RF-IPPE”, Obninsk, Russia \\ ${ }^{2}$ JSC “AKME-Engineering”, Moscow, Russia \\ Email: *toshinsky@ippe.ru
}

How to cite this paper: Gulevich, A.V., Eliseev, V.A., Komlev, O.G., Tormyshev, I.V. and Toshinsky, G.I. (2020) Americium Transmutation in the SVBR-100 Reactor. World Journal of Nuclear Science and Technology, 10, 116-128.

https://doi.org/10.4236/wjnst.2020.103011

Received: June 2, 2020

Accepted: July 10, 2020

Published: July 13, 2020

Copyright (c) 2020 by author(s) and Scientific Research Publishing Inc. This work is licensed under the Creative Commons Attribution International License (CC BY 4.0).

http://creativecommons.org/licenses/by/4.0/

\section{Open Access}

\begin{abstract}
One of the postponed problems of nuclear power (NP) is the problem of the management of long-lived radioactive waste (RAW), and, first of all, with minor actinides (MA), of which americium-241 is the most difficult. The aim of this work is to study the efficiency of americium transmutation in a fast reactor with a heavy liquid metal coolant lead-bismuth eutectic alloy. The article presents the results of calculations of the transmutation of americium in the SVBR-100 reactor using standard uranium oxide fuel with the addition of americium-241. The obtained values of the rate of transmutation of americium are compared with similar values for the SVBR-100 reactors on MOX-fuel and in the $\mathrm{BN}-800$ reactor.
\end{abstract}

\section{Keywords}

SVBR-100, Fast Reactor, Nuclear Power, Lead-Bismuth Eutectic, Minor Actinides, Americium, Nuclear Fuel Cycle, Neutron Spectrum, Core

\section{Introduction}

One of the postponed problems of nuclear power (NP) is the problem of the treatment of long-lived radioactive waste (RAW), and, first of all, with minor actinides (MA). Of the minor actinides (Neptunium, Americium, Curium), ${ }^{237} N p$ poses the least radioecological hazard due to the very long half-life $\left(\mathrm{T}_{1 / 2}=2.1 \times\right.$ $10^{6}$ years). Therefore, its transmutation should be considered last. At the same time, when storing ${ }^{237} \mathrm{~Np}$ in large quantities, it is necessary to take into account nuclear safety problems, since its critical mass for the fast neutron spectrum is only $60 \mathrm{~kg}$ (Ref. [1]) (in the thermal spectrum, ${ }^{237} \mathrm{~Np}$ does not have a critical mass, since its fission cross section has a threshold character).

Curium transmutation is also impractical, since the main part of its isotopes 
${ }^{243} \mathrm{Cm}$ and ${ }^{244} \mathrm{Cm}$, which are alpha emitters, on the contrary, have relatively short half-lives (29 years and 18 years), and it is expediently to keep them in controlled storage for about 100 years before decaying into plutonium isotopes that return to the closed nuclear fuel cycle (CNFC) of the future large-scale nuclear power. In this case, of course, it is necessary to take into account the high specific heat release of curium.

The greatest difficulty in handling is represented by americium isotopes $\left({ }^{241} \mathrm{Am},{ }^{242 \mathrm{~m}} \mathrm{Am},{ }^{243} \mathrm{Am}\right)$, due to their orders of magnitude higher specific radioactivity compared to ${ }^{237} \mathrm{~Np}$ and high gamma radiation ${ }^{241} \mathrm{Am}$, formed during ${ }^{241} \mathrm{Pu}$ beta decay. The americium isotopes have long half-lives in comparison with the curium isotopes, which makes it unpromising for their long-term storage until they decay into curium isotopes. Their half-life equals 432, 141 and 7370 years, respectively. The ${ }^{242 \mathrm{~m}} A m$ and ${ }^{243} A m$ isotopes are formed upon neutron capture by the ${ }^{241} P u$ and ${ }^{242} P u$ isotopes.

Fast reactors (FR), working in the CNFC, are able to solve the postponed problem of handling MA by their multiple recycling. However, at the same time, the complexity of manufacturing fresh recycled fuel and subsequent handling (before loading it into the reactor) increases significantly due to the high radioactivity and heat release of fuel rods and fuel assemblies (FAs). In this regard, various methods of nuclear transmutation of americium in the fast neutron spectrum of a critical or subcritical (with an accelerator) specialized transmutation reactor are considered, when americium is fissioned and converted into ordinary relative short-lived fission products, and when neutrons are captured, it becomes isotopes of transuranic elements.

In the earlier work (Ref. [2]), the possibility of transmutation of minor actinides in the SVBR-100 reactor with MOX-fuel was considered. In one of the options considered in this work, core loading was formed from $1360 \mathrm{~kg}$ of plutonium $\left({ }^{238} \mathrm{Pu} /{ }^{239} \mathrm{Pu} /{ }^{240} \mathrm{Pu} /{ }^{241} \mathrm{Pu} /{ }^{242} \mathrm{Pu}=1.86 \% / 59.81 \% / 24.85 \% / 7.67 \% / 5.81 \%\right)$ and $218 \mathrm{~kg}$ of minor actinides $\left({ }^{237} \mathrm{~Np} /{ }^{241} \mathrm{Am} /{ }^{243} \mathrm{Am}=39.57 \% / 53.24 \% / 7.19 \%\right)$. With a campaign duration of 76,000 eff. h. the mass of MA at the end of the campaign was $165 \mathrm{~kg}$, thus, the decrease in minor actinides was $53 \mathrm{~kg}$.

Since MOX-fuel contains a significant amount of plutonium, during the operation of the reactor with this fuel, ${ }^{241} A m$ is produced due to $\beta$-decay present in the initial fuel and formed during the operation of the reactor ${ }^{241} \mathrm{Pu}$. Thus, the efficiency of MA transmutation in a MOX-fuel reactor is reduced. A more effective option would be to transmute $\mathrm{MA}$ in a reactor operating on uranium oxide fuel, in which plutonium is initially absent.

In [3], the transmutation of americium into an FR with a sodium coolant (BN-800) was considered, where the rates of its conversion to both fission products and ${ }^{242} \mathrm{Cm}$ upon radiative capture of ${ }^{241} \mathrm{Am}$ neutrons were determined. At a neutron energy lower than $0.8 \mathrm{MeV}$, its cross section for radiation capture significantly exceeds the cross section for fission (see Figure 1). Due to the stronger elastic moderation on sodium nuclei (compared with lead and bismuth), the neu- 
tron spectrum in the $\mathrm{BN}-800$ reactor is somewhat softer than in the SVBR-100 (see Figure 2). This should also lead to a higher transmutation rate of ${ }^{241} \mathrm{Am}$ than in the SVBR-100 reactor, ceteris paribus.

The influence of the hardness of the neutron spectrum on the ratio of the rates of neutron capture and fission processes can be seen from a comparison of the parameter $\alpha_{A m}$ (ratio of radiation capture and fission cross sections averaged over the neutron spectrum) of BN-800 reactors (Ref. [3]) and the SVBR-100 reactor (this work), where they are equal to $\sim 45$ and 5 , respectively, due to a sharp decrease the capture cross section of ${ }^{241} \mathrm{Am}$ at a neutron energy above 0.8 $\mathrm{MeV}$ and, conversely, by increasing its fission cross section. Therefore, the rate of formation of ${ }^{242} \mathrm{Cm}$, having a half-life of about 165 days, with high specific heat release, all else being equal, in the $\mathrm{BN}-800$ reactor will be significantly higher

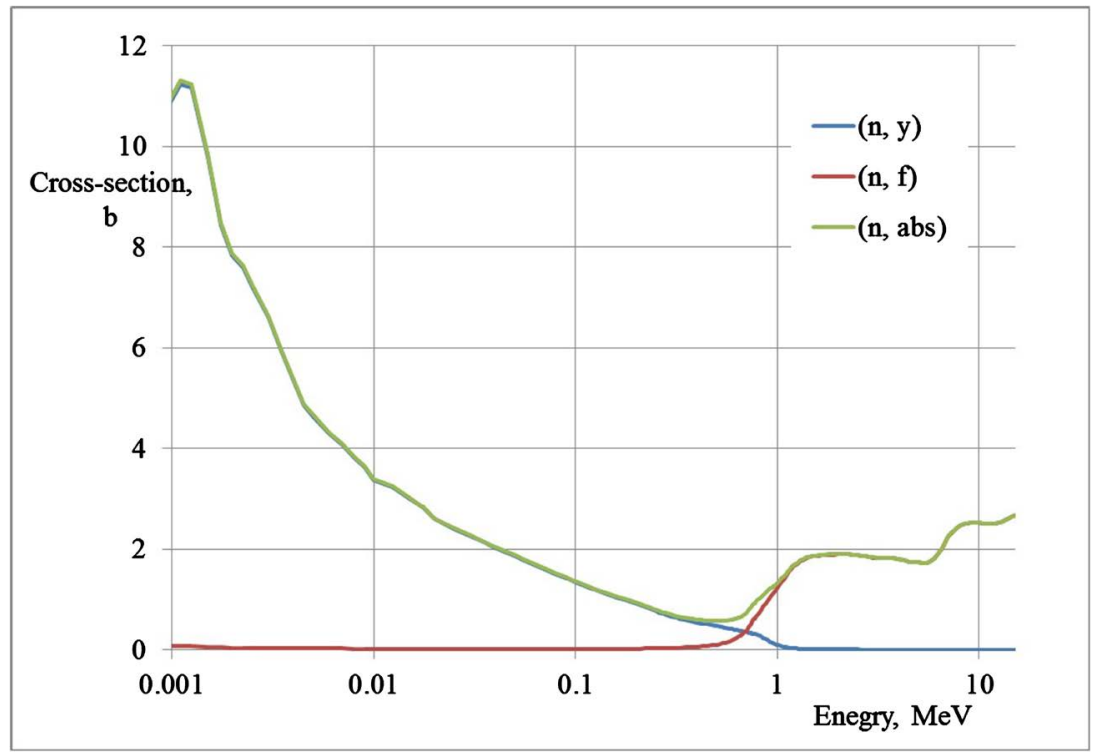

Figure 1. Americium-241 absorption, fission and capture cross-sections energy dependence.

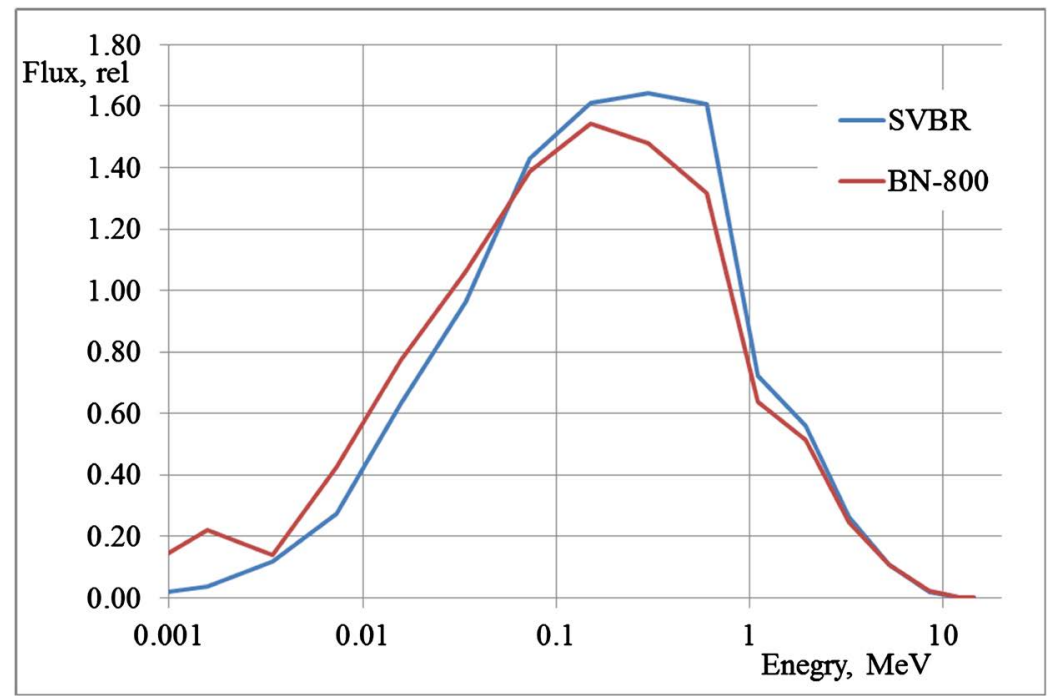

Figure 2. Neutron spectrum in SVBR-100 and BN-800 reactors. 
than in the reactor SVBR 100.

In this work, we consider the transmutation of americium extracted from spent nuclear fuel (SNF) of VVER-1000 after 15 years of storing, with a typical isotopic

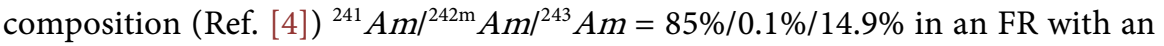
HLMC, in particular, in the SVBR-100 reactor with uranium oxide fuel.

\section{Description of Calculated Model}

For calculations, the design of the core of the SVBR-100 reactor using uranium oxide fuel was adopted, corresponding to that described in Ref. [2].

The diameter of the core is $1645 \mathrm{~mm}$, the height of the active part of the fuel rods is $900 \mathrm{~mm}$. The total number of fuel rods in the core is $\sim 12,500$. The fuel rods are arranged on a triangular lattice with a pitch of $13.6 \mathrm{~mm}$ and are combined into fuel assemblies, the total number of which is 61 .

Container type fuel elements, the diameter of the cladding along the cylindrical part is $12 \times 0.4 \mathrm{~mm}$, the cladding is a tube with 4 spiral spacing ribs, the diameter of the cladding along the ribs is $13.5 \mathrm{~mm}$. Fuel pellets $\left(\mathrm{UO}_{2}\right)$ have an average enrichment in uranium-235 of about $16.5 \%$. The density of oxide fuel was taken equal to $10.6 \mathrm{~g} / \mathrm{cm}^{3}$, the full loading on heavy atoms (h.a.) is $\sim 9.1$ tons. The radial power distribution is equalized by physical profiling of the content of fissile nuclei in four radial zones with an increase in the content of fissile nuclei from $\sim 13 \%$ to $19.5 \%$ from the center to the periphery.

Volume fractions of materials in a physical cell corresponding to one fuel element are given below:

- volume fraction of fuel $\sim 0.615$;

- volume fraction of steel $\sim 0.105$;

- volume fraction of the coolant $\sim 0.28$.

A steel reflector is located in the lower part of the fuel rod, under the steel reflector there is a compensation volume for collecting gaseous fission products (FPs) entering the cladding.

Above and below are the structures of the reactor removing part with the core, which ensure the placement of fuel rods and fuel assemblies in the core and the possibility of their loading and unloading (upper and lower grids of fuel assemblies).

On the sides, the core is surrounded by a reflector, which is a steel box filled with lead-bismuth eutectic (LBE).

The reactivity margin is compensated by a system of control rods placed along the axis of the fuel assembly. The rods form a triangular lattice in the core with a pitch of $224 \mathrm{~mm}$. The number of rods and their design is determined in accordance with the requirements for compensating for changes in reactivity during the campaign. The cross-sectional diagram of the core with the maximum number of rods (37 pcs.) is shown in Figure 3.

The calculations were carried out using the REACTOR program package (Ref. [5], used to substantiation the neutron-physical characteristics of fast reactors 


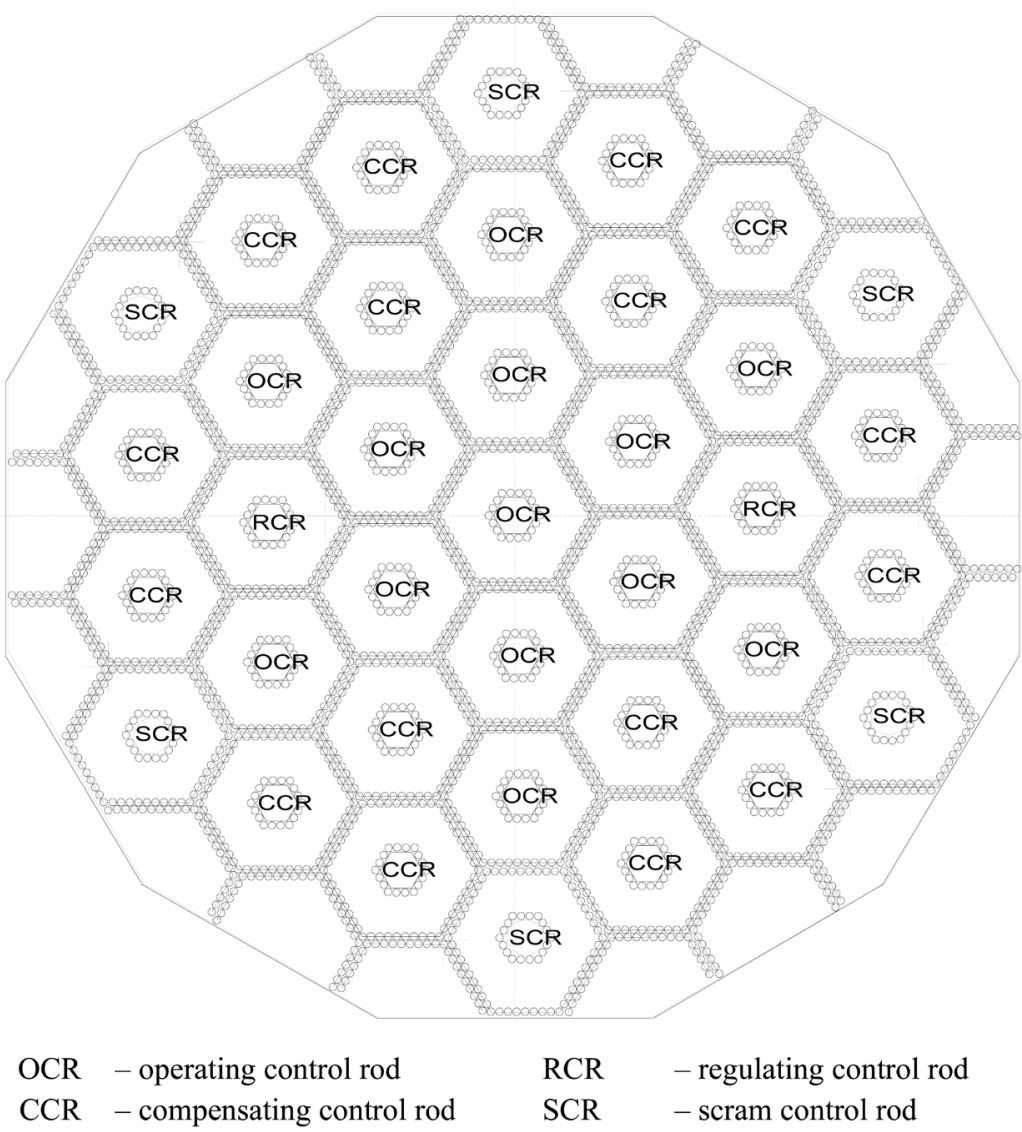

Figure 3. Diagram of the core with the 37 control rods.

with HLMCs. The R-Z model of the core was used in the calculations, such an approximation makes it possible to fairly accurately estimate the reactor characteristics from the campaign-heavy atom balances and reactivity drop.

The starting load of the first campaign was formed as follows. ${ }^{235} U$ load left unchanged like Ref. [2]. Americium was added to the fuel, replacing ${ }^{238} U$ in the "nucleus to nucleus" ratio. The load with americium was taken to be $218 \mathrm{~kg}$, the total load of $N p$ and $A m$ in Ref. [2], which corresponds to its mass content in the fuel of about $2.5 \%$. In this case, the heat release from americium in one fresh fuel assembly ( $3.6 \mathrm{~kg} \mathrm{Am}$ ) will be $0.3 \mathrm{~kW}$, and in the spent fuel assembly one month after the reactor shutdown, taking into account the residual heat and heat generation of minor actinides, $\sim 15 \mathrm{~kW}$, which must be taken into account the technology of refueling of the SVBR-100 reactor, designed today for heat generation in spent fuel assemblies of $9 \mathrm{~kW}$.

Core loads for subsequent campaigns were formed according to the following algorithm. For the second campaign, the fuel load is similar to the start one. The SNF of the first campaign is used to form the load for the third campaign after seven years of storage and reprocessing. In this case, the remaining isotopes of uranium and americium are used, enriched uranium is added instead of removed fission products to restore the reactivity margin, as well as external americium of the accepted isotopic composition from the SNF of the thermal reactors 
to make up for its loss.

It is assumed that the extracted $\mathrm{Pu}$ will be used in the CNFC of large-scale nuclear power as a fuel for FRs. All MAs are separated and are not used in the calculations. Neptunium and curium go to their storage facilities, $N p$-for long-term storage until they are sent for transmutation after the completion of the transmutation of accumulated americium, and $\mathrm{Cm}$-for about 100 years until its isotopes are converted into isotopes of plutonium and returned to the nuclear fuel cycle. According to a similar algorithm, the load of the fourth campaign is formed from the SNF of the second campaign, the load of the fifth from SNF of the third and so on.

Reactor calculated model is presented in Figure 4.

The choice of SNF recycle time for seven years is associated with the features of the fuel cycle of the SVBR-100 reactor. The core of the SVBR-100 reactor is reloaded immediately, but after the end of the campaign. The calendar duration of the campaign in the variant with uranium fuel is 7 years (corresponding to 50,000 eff. hours). Thus, SNF unloaded from the reactor can be used to form new loading of the SVBR-100 core not earlier than after 7 years.

\section{The Results Obtained and Their Discussion}

The results of the calculation of the main characteristics of the consumption and production of actinides during the first 32 campaigns of the SVBR-100 reactor are presented in Figures 5-8 and in Table 1.

As can be seen from Figure 5, the producing share of $P u$ during fuel recycling is reduced, since ${ }^{238} U$ is gradually replaced by the ${ }^{236} U$ isotope generated from ${ }^{235} U$. The equilibrium fraction of ${ }^{236} U$ in the isotopic vector of uranium is $\sim 13 \%$.

In the steady state, burning (conversion into fission products) and removal (conversion to other isotopes of transuranic elements) of americium (in total

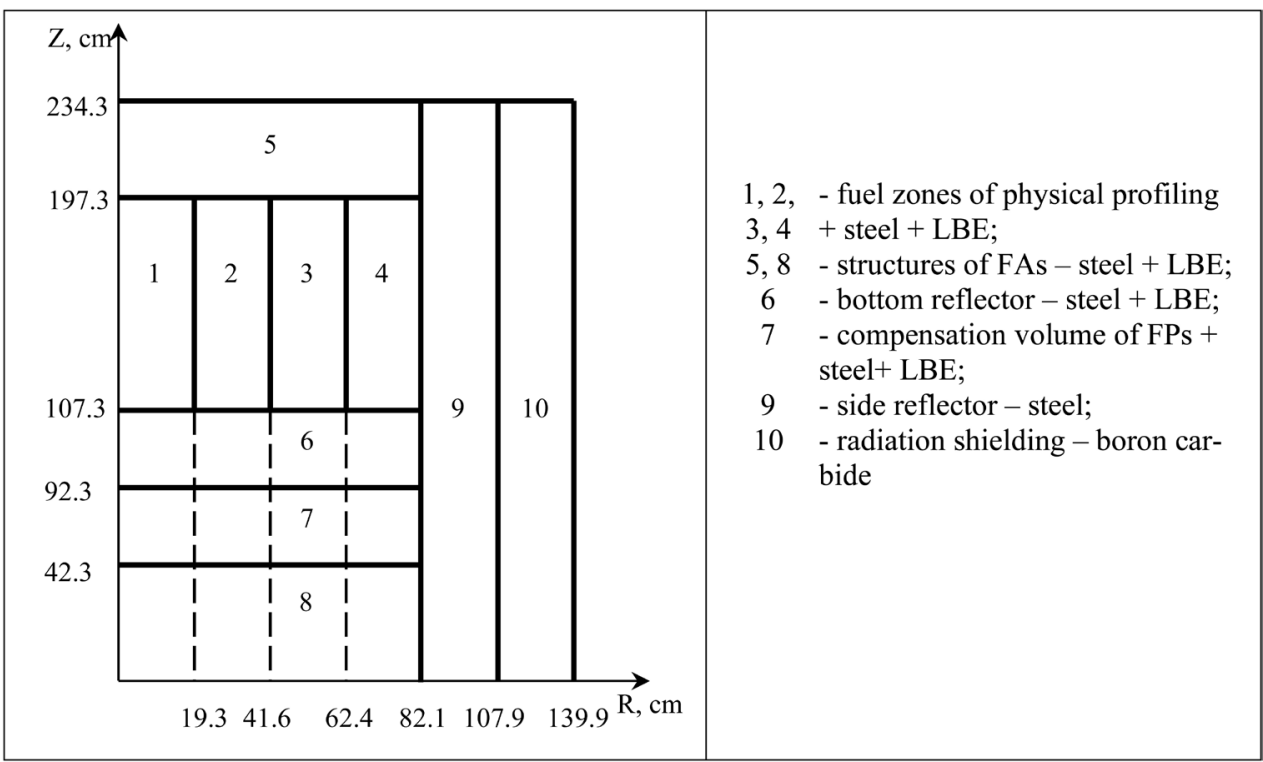

Figure 4. Reactor calculated model. 
Mass, $\mathrm{kg}$

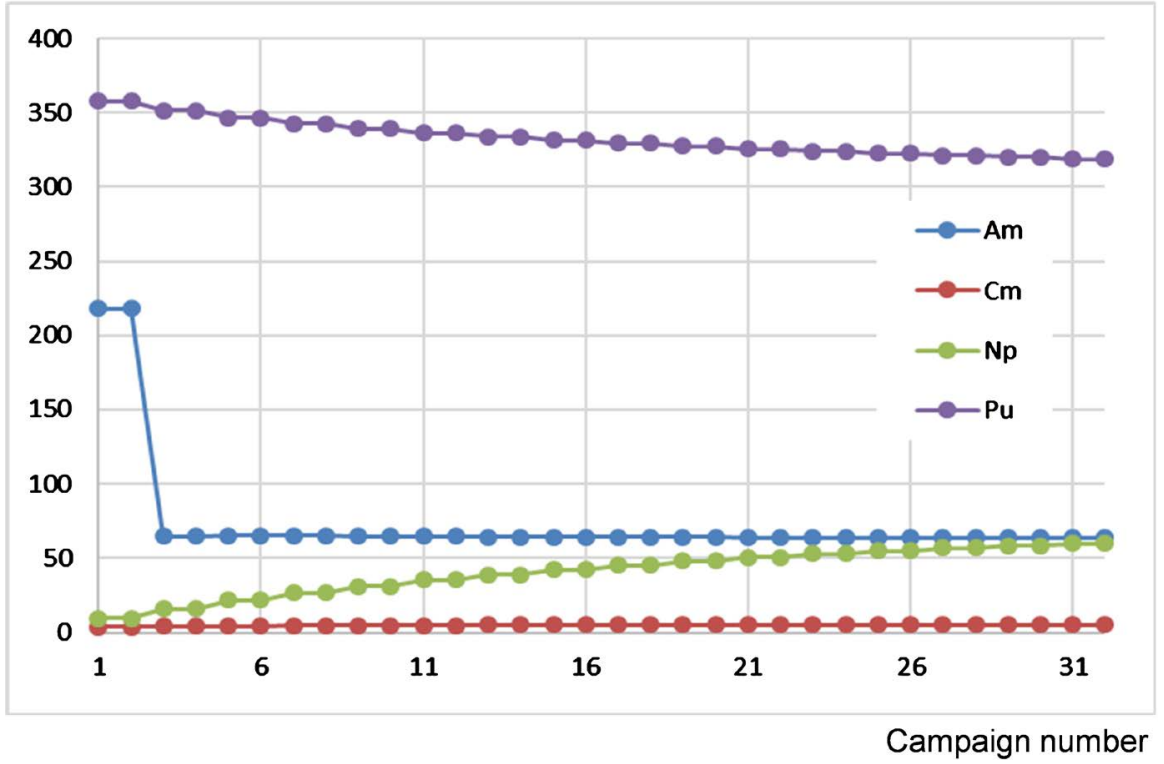

Figure 5. Americium consumption and production of curium, neptunium and plutonium in the first 32 reactor campaigns.

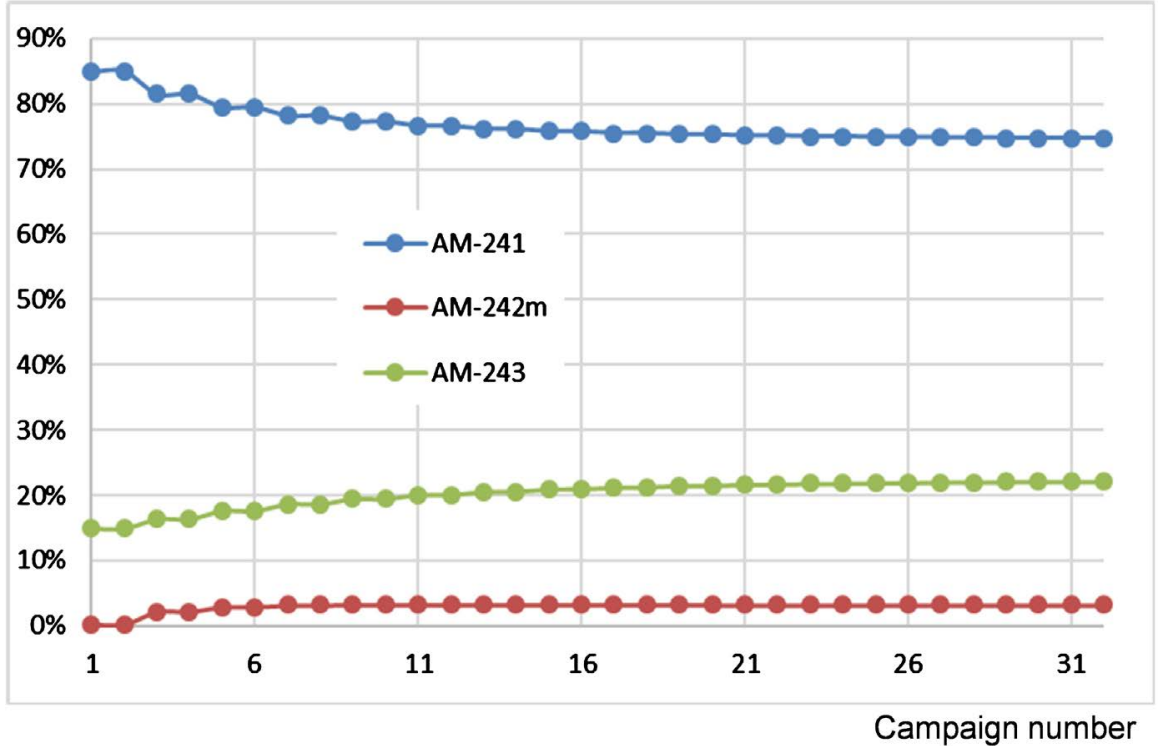

Figure 6. The relative content of americium isotopes in the fuel composition in the first 32 reactor campaigns.

transmutation) will amount to $\sim 63 \mathrm{~kg}$ per campaign. Taking into account the first loads, into which $218 \mathrm{~kg}$ of americium is introduced, it will take about 2000 reactor-years to transmute the accumulated currently in the VVER americium reactors (about 20 tons) with one SVBR-100 reactor.

When is used of a modular NPP based on SVBR-100 reactor facility (RF) with a capacity of $1 \mathrm{GWe}$ for americium transmutation, all the americium accumulated will be used for loading into the cores of SVBR-100 reactors 182 years after the NPP was put into operation (2.18 tons will be used to form the first loads of 


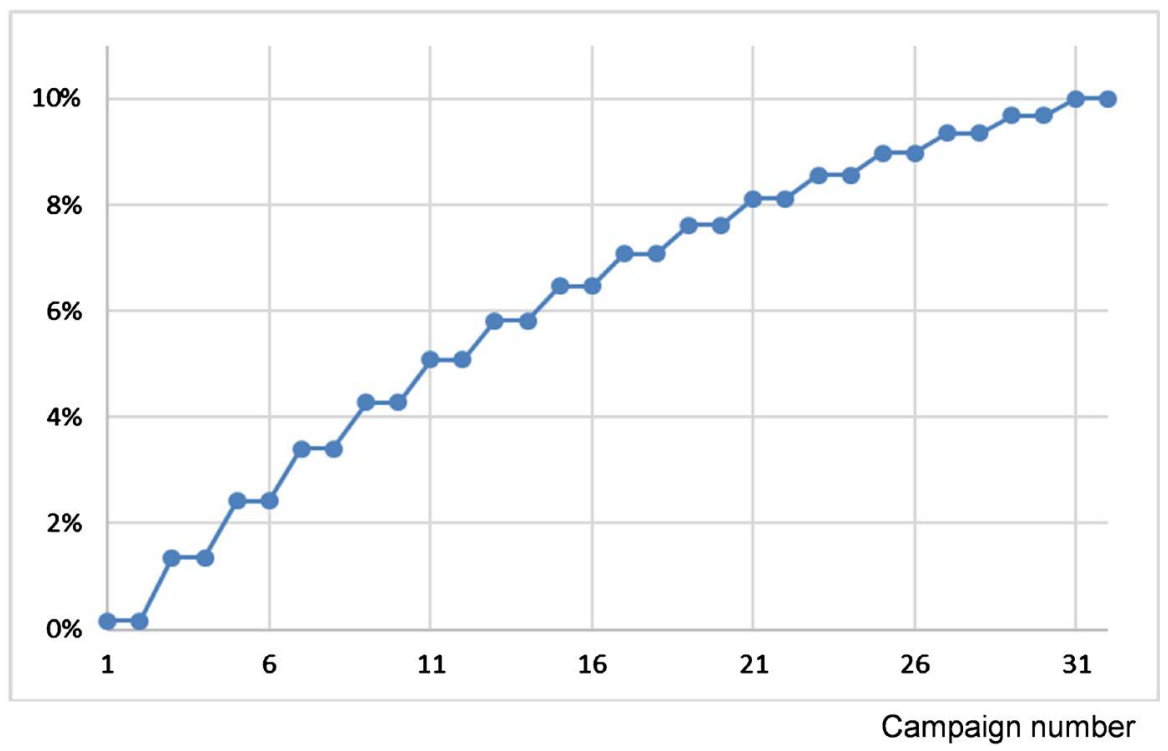

Figure 7. The proportion of ${ }^{236} \mathrm{U}$ in the total mass of uranium isotopes in the core loading for the first 32 campaigns.

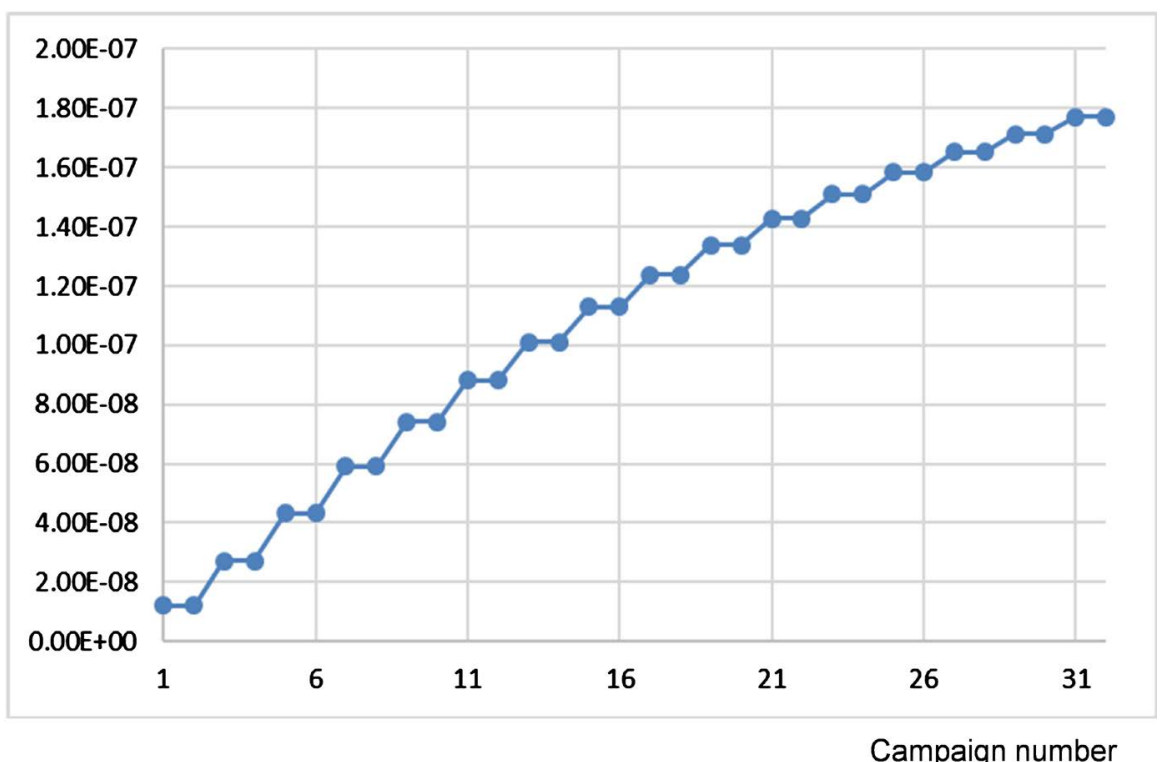

Figure 8. The share of ${ }^{232} \mathrm{U}$ in the total mass of uranium isotopes in spent nuclear fuel in the first 32 campaigns.

modules, 2.18 tons-to form the second loads, and taking into account the formation of loadings for the next 25 campaigns, the total mass of americium loaded into the cores of the reactors will reach 20.11 tons) - that is, the accumulated amount of americium will be utilized. For transmutation of the indicated amount of americium over the designated service life of the SVBR-100 reactor (60 years), the total capacity of the power units of modular NPPs based on the SVBR-100 reactor will be 3 GWe.

In the equilibrium operating mode, the production of plutonium in one reactor per campaign will be $\sim 307 \mathrm{~kg}$, the share of ${ }^{238} \mathrm{Pu}$ in the produced plutonium 
Table 1. Masses of actinides when loading and unloading fuel in the first campaign and in steady state.

\begin{tabular}{|c|c|c|c|c|c|c|c|}
\hline \multirow{2}{*}{$\begin{array}{l}\text { Isotope } \\
\text { Symbol }\end{array}$} & \multirow{2}{*}{$\begin{array}{c}\text { Half-life } \\
T_{1 / 2}\end{array}$} & \multicolumn{3}{|c|}{ First campaign } & \multicolumn{3}{|c|}{ Steady state } \\
\hline & & Loading, kg & Unloading, kg & Difference, kg & Loading, kg & Unloading, kg & Difference, $\mathrm{kg}$ \\
\hline $\mathrm{U}-232$ & 68.9 years & $0.000 \mathrm{E}+00$ & $3.641 \mathrm{E}-05$ & $3.641 \mathrm{E}-05$ & $1.890 \mathrm{E}-03$ & $1.373 \mathrm{E}-03$ & $-5.167 \mathrm{E}-04$ \\
\hline $\mathrm{U}-233$ & $1.592 \mathrm{E}+5$ лет & $0.000 \mathrm{E}+00$ & $4.386 \mathrm{E}-04$ & $4.386 \mathrm{E}-04$ & $2.203 \mathrm{E}-03$ & $1.985 \mathrm{E}-03$ & $-2.179 \mathrm{E}-04$ \\
\hline U-234 & $2.455 \mathrm{E}+5$ years & $1.406 \mathrm{E}+01$ & $1.255 \mathrm{E}+01$ & $-1.502 \mathrm{E}+00$ & $1.919 \mathrm{E}+01$ & $1.695 \mathrm{E}+01$ & $-2.236 \mathrm{E}+00$ \\
\hline U-235 & $7.04 \mathrm{E}+8$ years & $1.529 \mathrm{E}+03$ & $9.708 \mathrm{E}+02$ & $-5.578 \mathrm{E}+02$ & $1.529 \mathrm{E}+03$ & $9.828 \mathrm{E}+02$ & $-5.458 \mathrm{E}+02$ \\
\hline U-236 & $2.342 \mathrm{E}+7$ years & $1.406 \mathrm{E}+01$ & $1.209 \mathrm{E}+02$ & $1.068 \mathrm{E}+02$ & $1.173 \mathrm{E}+03$ & $1.173 \mathrm{E}+03$ & $3.000 \mathrm{E}-01$ \\
\hline $\mathrm{U}-238$ & $4.468 \mathrm{E}+9$ years & $7.398 \mathrm{E}+03$ & $6.935 \mathrm{E}+03$ & $-4.635 E+02$ & $6.225 \mathrm{E}+03$ & $5.838 \mathrm{E}+03$ & $-3.867 \mathrm{E}+02$ \\
\hline PU-236 & 2.858 years & $0.000 \mathrm{E}+00$ & $7.571 \mathrm{E}-05$ & $7.571 \mathrm{E}-05$ & $0.000 \mathrm{E}+00$ & $6.330 \mathrm{E}-04$ & $6.330 \mathrm{E}-04$ \\
\hline PU-238 & 87.7 years & $0.000 \mathrm{E}+00$ & $2.603 \mathrm{E}+01$ & $2.603 \mathrm{E}+01$ & $0.000 \mathrm{E}+00$ & $3.072 \mathrm{E}+01$ & $3.072 \mathrm{E}+01$ \\
\hline PU-239 & 24110 years & $0.000 \mathrm{E}+00$ & $3.067 \mathrm{E}+02$ & $3.067 \mathrm{E}+02$ & $0.000 \mathrm{E}+00$ & $2.560 \mathrm{E}+02$ & $2.560 \mathrm{E}+02$ \\
\hline PU-240 & 6561 years & $0.000 \mathrm{E}+00$ & $1.519 \mathrm{E}+01$ & $1.519 \mathrm{E}+01$ & $0.000 \mathrm{E}+00$ & $1.256 \mathrm{E}+01$ & $1.256 \mathrm{E}+01$ \\
\hline PU-241 & 14.329 years & $0.000 \mathrm{E}+00$ & $4.962 \mathrm{E}-01$ & $4.962 \mathrm{E}-01$ & $0.000 \mathrm{E}+00$ & $3.993 \mathrm{E}-01$ & $3.993 \mathrm{E}-01$ \\
\hline PU-242 & $3.75 \mathrm{E}+50$ years & $0.000 \mathrm{E}+00$ & $6.736 \mathrm{E}+00$ & $6.736 \mathrm{E}+00$ & $0.000 \mathrm{E}+00$ & $5.773 \mathrm{E}+00$ & $5.773 \mathrm{E}+00$ \\
\hline PU-244 & $8.13 \mathrm{E}+7$ years & $0.000 \mathrm{E}+00$ & $1.815 \mathrm{E}-03$ & $1.815 \mathrm{E}-03$ & $0.000 \mathrm{E}+00$ & $2.617 \mathrm{E}-03$ & $2.617 \mathrm{E}-03$ \\
\hline NP-235 & 396.1 days & $0.000 \mathrm{E}+00$ & $5.314 \mathrm{E}-08$ & $5.314 \mathrm{E}-08$ & $0.000 \mathrm{E}+00$ & $4.909 \mathrm{E}-07$ & $4.909 \mathrm{E}-07$ \\
\hline NP-236 & $153 \mathrm{E}+3$ years & $0.000 \mathrm{E}+00$ & $5.968 \mathrm{E}-05$ & $5.968 \mathrm{E}-05$ & $0.000 \mathrm{E}+00$ & $5.885 \mathrm{E}-04$ & $5.885 \mathrm{E}-04$ \\
\hline NP-237 & $2.144 \mathrm{E}+6$ years & $0.000 \mathrm{E}+00$ & $8.354 \mathrm{E}+00$ & $8.354 \mathrm{E}+00$ & $0.000 \mathrm{E}+00$ & $7.400 \mathrm{E}+01$ & $7.400 \mathrm{E}+01$ \\
\hline AM-241 & 432.6 years & $1.853 \mathrm{E}+02$ & $1.240 \mathrm{E}+02$ & $-6.133 E+01$ & $1.625 \mathrm{E}+02$ & $1.099 \mathrm{E}+02$ & $-5.262 \mathrm{E}+01$ \\
\hline AM242M & 141 years & $2.180 \mathrm{E}-01$ & $4.801 \mathrm{E}+00$ & $4.583 \mathrm{E}+00$ & $6.916 \mathrm{E}+00$ & $7.093 \mathrm{E}+00$ & $1.769 \mathrm{E}-01$ \\
\hline AM-243 & 7364 years & $3.248 \mathrm{E}+01$ & $2.607 \mathrm{E}+01$ & $-6.416 \mathrm{E}+00$ & $4.860 \mathrm{E}+01$ & $3.921 \mathrm{E}+01$ & $-9.395 \mathrm{E}+00$ \\
\hline CM-240 & 27 days & $0.000 \mathrm{E}+00$ & $1.747 \mathrm{E}-10$ & $1.747 \mathrm{E}-10$ & $0.000 \mathrm{E}+00$ & $1.517 \mathrm{E}-10$ & $1.517 \mathrm{E}-10$ \\
\hline CM-241 & 32.8 days & $0.000 \mathrm{E}+00$ & $1.948 \mathrm{E}-07$ & $1.948 \mathrm{E}-07$ & $0.000 \mathrm{E}+00$ & $1.694 \mathrm{E}-07$ & $1.694 \mathrm{E}-07$ \\
\hline CM-242 & 162.8 days & $0.000 \mathrm{E}+00$ & $3.004 \mathrm{E}+00$ & $3.004 \mathrm{E}+00$ & $0.000 \mathrm{E}+00$ & $2.599 \mathrm{E}+00$ & $2.599 \mathrm{E}+00$ \\
\hline CM-243 & 29.1 years & $0.000 \mathrm{E}+00$ & $2.382 \mathrm{E}-01$ & $2.382 \mathrm{E}-01$ & $0.000 \mathrm{E}+00$ & $1.975 \mathrm{E}-01$ & $1.975 \mathrm{E}-01$ \\
\hline CM-244 & 18.11 years & $0.000 \mathrm{E}+00$ & $4.327 \mathrm{E}+00$ & $4.327 \mathrm{E}+00$ & $0.000 \mathrm{E}+00$ & $6.239 \mathrm{E}+00$ & $6.239 \mathrm{E}+00$ \\
\hline CM-245 & 8423 years & $0.000 \mathrm{E}+00$ & $1.989 \mathrm{E}-01$ & $1.989 \mathrm{E}-01$ & $0.000 \mathrm{E}+00$ & $2.789 \mathrm{E}-01$ & $2.789 \mathrm{E}-01$ \\
\hline CM-246 & 4706 years & $0.000 \mathrm{E}+00$ & $5.177 \mathrm{E}-03$ & $5.177 \mathrm{E}-03$ & $0.000 \mathrm{E}+00$ & $7.048 \mathrm{E}-03$ & $7.048 \mathrm{E}-03$ \\
\hline CM-247 & $1.56 \mathrm{E}+7$ years & $0.000 \mathrm{E}+00$ & $8.112 \mathrm{E}-05$ & $8.112 \mathrm{E}-05$ & $0.000 \mathrm{E}+00$ & $1.065 \mathrm{E}-04$ & $1.065 \mathrm{E}-04$ \\
\hline CM-248 & $3.48 \mathrm{E}+5$ years & $0.000 \mathrm{E}+00$ & $2.299 \mathrm{E}-06$ & $2.299 \mathrm{E}-06$ & $0.000 \mathrm{E}+00$ & $2.927 \mathrm{E}-06$ & $2.927 \mathrm{E}-06$ \\
\hline
\end{tabular}

will be $\sim 10 \%$, which will determine the heat release in plutonium of $0.56 \mathrm{~kW} / \mathrm{kg}$ ${ }^{238} \mathrm{Pu}$. The mass of curium isotopes in SNF at the end of each campaign will be $9.3 \mathrm{~kg}$ (specific heat release is $36 \mathrm{~kW} / \mathrm{kg}$ for the composition of curium produced in the considered reactor ${ }^{242} \mathrm{Cm} /{ }^{243} \mathrm{Cm} /{ }^{244} \mathrm{Cm}=28 \% / 2 \% / 67 \%$ ), the mass produced for a neptunium per one campaign is $\sim 75 \mathrm{~kg}$. 
The fraction of ${ }^{232} U$ in the equilibrium vector of uranium isotopes will be $\sim 2.3$ $\times 10^{-7}$. With the operation of the SVBR reactor in the nuclear fuel cycle using MOX-fuel with make-up depleted uranium, the fraction of ${ }^{232} U$ after 9 recycles reaches $3 \times 10^{-7}$. It should be noted that in both the first and second cases, the content of ${ }^{232} U$ significantly exceeds the limit content given in Ref. [6] (with ${ }^{232} U{ }^{235} U<1.1 \times 10^{-7}$ ), which determines the possibility of removing ${ }^{232} U$ from the regenerate uranium during gas centrifugal separation of its isotopes.

This limitation is due to the fact that ${ }^{232} U$, which is an $\alpha$-emitter with a half-life of about 70 years, has ${ }^{228} \mathrm{Th}$ as a daughter nucleus with a half-life of 1.9 years, at the end of the chain of radioactive transformations of which, short-lived ${ }^{208} \mathrm{Tl}$ is formed, without long delay, which is a source of hard gamma radiation with an energy of gamma rays of $2.6 \mathrm{MeV}$. The same reason makes it difficult to handle fresh recycled fuel in the CNFC of $T h{ }^{233} U$, in which ${ }^{232} U$ is accumulated in large quantities. The importance of ${ }^{232} U$ for its removal from uranium regenerate can be significantly reduced if the storage time between its chemical separation from SNF and its transfer to the separation is reduced to a value significantly less than 1.9 years.

The rate of production of americium by thermal reactors (TR) and, accordingly, the number of FRs for its transmutation can be significantly reduced by decreasing the time of storing SNF before reprocessing, since ${ }^{241} \mathrm{Am}$ is a daughter product of ${ }^{241} \mathrm{Pu}$, which has a half-life about 14 years. In this case, the separated plutonium will be used in the CNFC of two-component NP as fuel component in a mixed fuel of FRs. Estimates show that when the VVER SNF storage time is reduced from 15 to three years, the required number of transmuting reactors is halved. To realize this possibility, it will require the development and industrial mastered of more complex methods for reprocessing SNF due to its higher radioactivity and, accordingly, heat release. At the same time, a reduction in SNF storing time will lead to an improvement in the plutonium isotope vector due to an increase in ${ }^{241} \mathrm{Pu}$ content.

It should be noted that the rate of americium transmutation in the SVBR-100 reactor can be increased in proportion to the increase in the amount of americium loaded into the core (in Ref. [3], to the BN-800 reactor, the content of americium was considered up to $16 \%$, h.a.). However, the realization of this possibility is associated with the need to solve the problem of cooling spent fuel assemblies when they are unloaded from the reactor and loading fresh fuel assemblies with a high content of americium.

If we define the efficiency coefficient of americium transmutation $\left(\mathrm{ECT}_{A m}\right)$ as a percentage ratio of the amount of incinerated (fission plus capture) americium (all isotopes) to the amount of burned out (fission plus capture) ${ }^{235} \mathrm{U}$, then the value of $\mathrm{ECT}_{A m}$ for the SVBR-100 reactor on uranium oxide fuel will be, as can be obtained from the data listed in the table, about 11 percent. That is, for the transmutation of 20 tons of americium, it is necessary to burn 220 tons of ${ }^{235} \mathrm{U}$. At the same time, about 140 tons of plutonium will be returned to the NFC of 
large-scale nuclear power over the same period. For FRs operating on MOX-fuel, for which the breeding ratio is close to unity (BN-800) or slightly larger than unity (SVBR-100), such a definition of $\mathrm{ECT}_{A m}$ loses its meaning, since the amount of plutonium is practically does not decrease or even slightly increases.

As the estimates showed, the effective share of delayed neutrons in the SVBR-100 reactor with the addition of americium varies slightly compared to the base case. In the basic version, the effective share of delayed neutrons is $0.71 \%$ at the beginning of the campaign and $0.58 \%$ at the end of the campaign. For the SVBR-100 supplemented with $218 \mathrm{~kg}$ of americium in the first campaign, the effective share of delayed neutrons is $0.69 \%$ at the beginning of the campaign and $0.57 \%$ at the end of the campaign. In the established regime, the effective share of delayed neutrons at the beginning of the campaign is $0.66 \%$, and at the end of the campaign, $0.56 \%$. It can be expected that other safety characteristics will not change significantly due to the small proportion of americium added to the core.

It should be noted that in order to ensure the operation of transmutation reactors with their on-station CNFC (to reduce the volume of transportation), more complex and "dirty" CNFC, it will be necessary to create a transport infrastructure for transporting separated MA from the CNFC facilities to the transmutation fast reactors sites, and vice versa transportation of plutonium extracted from SNF of transmutation fast reactors to the CNFC enterprises of large-scale nuclear power. These issues require a separate study.

\section{Conclusions}

It was shown in Ref. [3] that $82 \mathrm{~kg}$ of americium can be transmuted in the $\mathrm{BN}-800$ reactor operating on MOX-fuel per year, including $71 \mathrm{~kg}$ in the core with its fuel content of about $2.5 \%$ and $11 \mathrm{~kg}$ in the side breeding zone. Thus, one $\mathrm{BN}-800$ reactor incinerates americium produced by 2.8 VVER-1000 reactors, or in terms of the same power, the BN reactor with a capacity of $1 \mathrm{GWe}$ incinerates americium generated per year from 3.5 VVER-1000 reactors. At the same time, however, a very small part of americium is converted into fission products, and its main share is converted to ${ }^{242} \mathrm{Cm}$ with a specific heat release of $36 \mathrm{~kW} / \mathrm{kg}$ compared with $0.08 \mathrm{~kW} / \mathrm{kg}$ for ${ }^{241} \mathrm{Am}$ and $0.9 \mathrm{~kW} / \mathrm{kg}$ for ${ }^{244} \mathrm{Cm}$. Bearing in mind that the half-life of ${ }^{242} \mathrm{Cm}$ is about 165 days, its high content in the composition of curium isotopes will make it difficult to reduce the storage time of spent nuclear fuel before its reprocessing with the separation of MA and organize storage of the separated curium until it decays into plutonium isotopes.

In the previously considered variant of SVBR-100 using MOX fuel (Ref. [2]) for the campaign 76,000 eff. hours (10.6 years) $53 \mathrm{~kg}$ of MA is transmuted when the MA content in the fuel is $2.5 \%$, which gives a transmutation rate of $\sim 5 \mathrm{~kg} /$ year. Thus, SVBR-100 reactors using MOX fuel with a total capacity of $1 \mathrm{GWe}$ can incinerate americium, which is produced per year, from 1.7 VVER-1000 reactors.

The variant of the SVBR-100 reactor based on uranium oxide fuel containing about $2.5 \%$ americium considered in this work, while working in the CNFC ac- 
cording to the described algorithm, allows to incinerate $63 \mathrm{~kg}$ of americium for 50,000 effective hours or $9 \mathrm{~kg}$ per year. Thus, SVBR-100 reactors with a total capacity of $1 \mathrm{GWe}$ can incinerate americium produced by three VVER-1000 reactors per year. The comparison shows that the transmutation of americium in the core of SVBR-100 with uranium fuel is 1.8 times more efficient than in the core with MOX-fuel and 14 percent lower than in the $\mathrm{BN}-800$ reactor.

Since ${ }^{241} \mathrm{Am}$ is a product of ${ }^{241} \mathrm{Pu}$ radioactive decay, with a half-life of about 14 years, the amount of americium generated during storage of SNF of VVER reactors and requiring transmutation can be significantly reduced by reducing the storing time of VVER SNF before reprocessing. Accordingly, the required number of transmutation fast reactors can be reduced.

To realize this opportunity, it will require the development and industrial development of "dry" SNF reprocessing methods, in which there is no radiolysis and hydrogen release inherent in hydro-chemical reprocessing, and restrictions on the amount of fissile material in the reprocessing apparatus are reduced due to the absence of a moderator neutrons.

Since americium differs from other transplutonium elements in the increased volatility that occurs during sintering of fuel pellets, it seems reasonable to use the vibrapack technology of manufacturing of uranium dioxide as a matrix containing the required amount of granular americium oxide (Ref. [7]).

Thus, the problem of handling minor actinides has a multifactorial nature, and its solution requires a systematic approach, taking into account the problems involved, performing technical and economic investigations of various transmutation options in the frame of the development strategy of a two-component nuclear energy system.

\section{Conflicts of Interest}

The authors declare no conflicts of interest regarding the publication of this paper.

\section{References}

[1] Sanchez, R., Loaiza, D., Kimpland, R., Hayes, D. Cappiello, C. and Chadwick, M. (2008) Criticality of a ${ }^{237} \mathrm{~Np}$ Sphere. Nuclear Science and Engineering, 158, 1-14. https://doi.org/10.13182/NSE08-A2734

[2] Novikova, N.N., Komlev, O.G. and Toshinsky, G.I. (2006) Neutronic and Physical Characteristics of Reactor SVBR-75/100 with Different Types of Fuel. Proceedings of ICAPP06, Reno, NV, 4-8 June 2006.

[3] Gulevich, A.V., Eliseev, V.A., Troyanov, V.M., et al. (2020) Possibility Americium Incineration in the Fast Reactors. Atomnaya Energia, 128, 82-87. (In Russian)

[4] Alyoshin, S.S., Bolshagin, N.F., Bychkova, N.A., et al. (2002) Characteristics of VVER-1000 with 1/3 Core Loaded by MOX Fuel with Plutonium from Surplus Russian Nuclear Weapons. Proceeding of PHYSOR 2002, Seoul, 7-10 October 2002.

[5] Komlev, O.G., Novikova, N.N., Trevgoda, M.M. and Filimonov, Ye.V. (2007) Status and Problems of Computation and Methodological Substantiation of Designing Works on Reactor Facilities with Lead-Bismuth Coolant. Izvestia Vuzov. Yadernaya 
Energetika, No. 1, 79-91. (In Russian)

[6] Arthur, W.B. (1977) Uranium-232 Production in Current Design LWRs. United States. https://doi.org/10.2172/5963522

[7] Troyanov, V.M. and Kisly, V.A. (2018) Using of Pyroelectrochemical Granulation Vibrapack Technologies for Americium Utilization. Atomnaya Energia, 124, 261-265. (In Russian)

\section{Abbreviation}

$\mathrm{BN}$ sodium fast reactor (in Russia)

CNFC closed nuclear fuel cycle

ECT efficiency coefficient transmutation

FPs fission products

FR fast reactor

FA fuel assembly

HLMC heavy liquid metal coolant

LBE lead-bismuth eutectic

MA minor actinides

MOX mixed oxide uranium plutonium

NP nuclear power

NPP nuclear power plant

RAW radioactive waste

SFR sodium fast reactor

SNF spent nuclear fuel

SVBR lead-bismuth cooled fast reactor

TR thermal reactor

VVER pressurized water reactor (in Russia) 